Funder, S. \& Johannessen, S. (1957). J. gen. Microbiol. 17, 117-119

\title{
The Membrane Filter as an Aid in the Cultivation and Identification of Fungi
}

\author{
BY S. FUNDER AND SYNNØVE JOHANNESSEN \\ Department of Bacteriology, Institute of Pharmacy, University of Oslo, Norway
}

\begin{abstract}
SUMMARY: A method of cultivating fungi on a membrane filter is described. The growth on the membrane appears to be more rapid than on solid media. After 2-3 days of growth a piece of the disk was dried and placed in immersion oil on a slide, thus rendering the membrane transparent and suitable for microscopic examination in transmitted light. The new method makes the use of plates, microcultures (slide cultures), etc., unnecessary. The mechanical breakage of the mycelial structures often encountered when species of mycelium have to be transferred to slides for microscopic examination is avoided. As only a small piece of the membrane is needed for microscopic examination, the growth on the membrane is allowed to continue as long as is required. Each time an inspection of the culture is required, a small piece of the disk is removed.
\end{abstract}

The 'molecular filter membrane' (MF) method has established itself as a valuable aid in sanitary bacteriology, especially in the bacteriological analysis of water, food products, beverages and other liquids. It has been shown by a number of workers that all micro-organisms which can be cultivated on a suitable medium can also be cultivated on the MF, when the MF is placed on that medium. After filtration of air, water or other fluids, the membrane may be stained, so as to make possible the direct microscopic examination of particles collected on the surface, including even such relatively large structures as fungal spores and pollen. Gordon, Ajello, Georg \& Zeidberg (1952) reported on the use of MF in the detection of typical spores of Microsporum gypseum and Histoplasma capsulatum from soil and water. Such a procedure is, of course, effective only for those organisms which produce distinctive and identifiable microscopic structures. For the great majority of fungi, however, the spores are not so characteristic as to render direct identification possible. In view of the very delicate structure of the sporophores or other characteristic mycelial structures, this method appears to be of no value for identification purposes. In order to identify a fungus, the general procedure is to cultivate it on a suitable medium in Petri dishes, flasks, etc. When the cultural morphology is to be studied, a piece of aerial mycelium is removed and placed on a slide. Such a procedure often leads to mechanical destruction of the mycelial structure and makes identification difficult. In order to overcome this, a slide culture is often of great value. In certain cases, however, growth in a small volume of medium is not altogether typical. The slide culture must, therefore, be additional to, but not a substitute for, examination of the plate culture. The slide culture involves additional work and may be of no value in cases of fungi with no typical aerial mycelium, sporophores, etc. A cultivation method, without the use of plates, and providing the possibility of transferring the 
entire mycelial structure directly to the microscope without any mechanical disturbances, would be of great value in the identification. The MF method showed promise in this direction, and this was the reason why the study was undertaken.

\section{METHODS}

Use was made of membrane filters manufactured by The Millipore Filter Corporation, U.S.A. and Membranfiltergesellschaft, Gøttingen. A sterile absorbent pad was placed at the bottom of a sterile Petri dish, standard size, and approximately $2 \mathrm{ml}$. sterile yeast water, double strength, was added, so that the pad was evenly moistened with the liquid. A sterile membrane filter was put on top, taking care to avoid the entrapment of air between the filter disk and the pad. Inoculation was made from cultures of fungi by streaking with a zig-zag motion over the surface of the moistened filter disk. The dish was incubated at room temperature for 2-3 days. When growth occurred, the entire $\mathrm{MF}$, or a piece of it, was removed from the dish and dried at $50^{\circ}$ for 20-30 min., or preferably at room temperature for 3-4 hr. A few drops of standard immersion oil ( $n=$ approx. 1.50) were put on a slide and a piece of the dried MF carrying the culture placed on top. After a few seconds the membrane was rendered almost completely transparent (Jannasch, 1954) as soon as the pores were filled with the immersion oil, the membrane having the same refractive index as the immersion oil. The specimen was now ready for inspection by microscope, using transmitted light.

\section{RESULTS}

The following organisms were cultivated according to the method described: Botrytis allii (Centraalbureau voor Schimmelcultures); Alternaria tenuis, Geotrichum candidum, Pullularia pullulans, Trichoderma lignorum (Professor A. E. Traaen, The Norwegian Agricultural College); Aspergillus flavus, Cladosporium sp., Monilia sitophila (Cand. pharm. O. Clausen, Institute of Pharmacy, University of Oslo); Syncephalastrum cinereum, Thamnidium elegans (Botanical Laboratory, University of Oslo); Mucor racemosus, Penicillium roqueforti, Rhizopus nigricans (Dr S. Funder, Institute of Pharmacy, University of Oslo).

In many cases only 2 days of growth were sufficient to reveal characteristic details for identification of the organisms. This is in accordance with Orlando \& Bolduan (1953) and Tsuneishi \& Goetz (1953) who observed that the growth in many cases was more rapid on MF than on solid media. When 2 days growth was not sufficient, the MF was kept for another day or more. At each inspection a new piece of the MF was treated as described, while the growth was allowed to continue on the remaining part of the disk. In Pl. 1 photomicrographs of some of the fungi which were studied are shown. 
Journal of General Microbiology, Vol. 17, No. 1

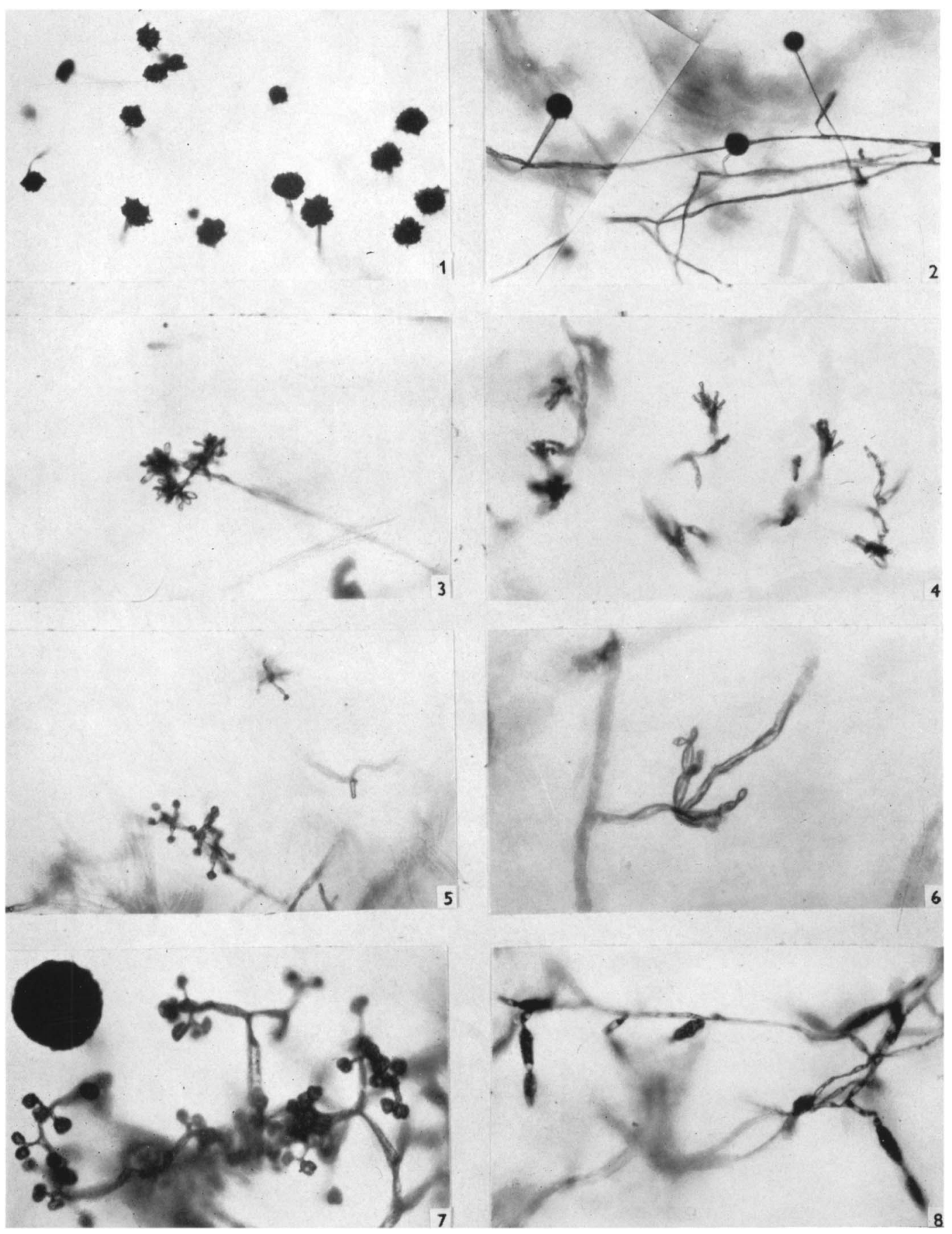

S. Funder and S. Johannessen-'The growth of Fungi on membranles. Plate 1

(Facing p. 119) 


\section{REFERENCES}

Gordon, M. A., AJello, L., Georg, L. K. \& Zeidberg, L. D. (1952). Microsporum gypseum and Histoplasmac apsulatum spores in soil and water. Science, 116, 208.

JANNASCH, H. W. (1954). Beitrag zur Methode der direkten mikroskopischen Untersuchung von Mikroorganismen auf Membranfiltern: Uber die Aufhellung der Filter. Zbl. Bakt. (1. Orig.), 161, 225.

Orlando, M. D. \& Bolduan, O. E. A. (1953). The application of the membrane filter to a variety of pathogenic bacteria and Fungi Imperfecti. Bact. Proc. (53rd. Gen. Meet.), p. 26.

TSUNEISHI, N. \& GoETz, A. (1953). Growth development and incubation of bacterial cultures on molecular filter membranes. Bact. Proc. (53rd Gen. Meet.), p. 26.

\section{EXPLANATION OF PLATE}

Fig. 1. Aspergillus flavus. $\times 75$.

Fig. 2. Mucor racemosus. $\times 75$.

Fig. 5. Trichoderma lignorum. $\times \mathbf{2 5 0}$.

Fig. 3. Botrytis alii. $\times 250$.

Fig. 6. Cladosporium sp. $\times 500$.

Fig. 4. Penicillium roqueforti. $\times \mathbf{2 5 0}$.

Fig. 7. Thamnidium elegans. $\times \mathbf{2 5 0}$.

Fig. 8. Alternaria tenuis. $\times 250$.

(Received 13 February 1957) 